\title{
Youth Media Participation: Global Perspectives
}

\author{
Sirkku Kotilainen ${ }^{1}$ \\ School of Communication, Media and Theatre, University of Tampere, Finland
}

\section{Annikka Suoninen}

The Finnish Youth Research Network and Research Centre for Contemporary Culture, University of Jyväskylä, Finland

\section{doi:10.5937/comman1329037K}

Summary: Researchers point out media participation as a growing phenomenon among audiences, especially among young people in western societies. We broaden the gaze outside Europe to more global perspectives on their media participation, based on the Comparative Research on Youth Media Participation (2009-2011), in which we have been studying the audience activities of young people, explored with questionnaires, interviews and media diaries of 11-18 years old in Argentina, Egypt, Finland and India. In this article the statistical results from the survey are reflected with Nico Carpentier's (2011) structuring four elements of media participation: identities as participatory subject positions in a communicative process; organizational structures supporting or declining the levels of participation; the available technology supporting or declining the participation process; and quality which the author relates to quality discourses in media production, including their participatory practices, aesthetics, performances, etc., which are based on the skills of the producerl user. Based on this reflection, the article suggests a discursive differentiation of the aspects of youth media participation. Moreover, the study suggests emphasis on media and information literacies together with participatory activities in relation to the media and in the research on media participation from the user's perspective.

Keywords: youth, media, media participation, access, motivation, comparative research

\footnotetext{
1 sirkku.kotilainen@uta.fi
} 


\section{Introduction}

Community services and social networking sites, such as YouTube and Facebook, along with Wikipedia and blogs, allow users to become engaged in public and social knowledge creation - both at the national level and international digital media cultures. These kind of online public media interest young people because they provide opportunities for interaction and creation in their own media work. Youth researchers talk about "mediated youth cultures", in which the uses of different media (e.g. the Internet, mobile phones, television) - as well as the modes of cultural expression, i.e. music, texts and images added to their multimodalities - are integrated into the everyday lives of the young through participatory cultures online (e.g. Hodkinson and Deicke, 2007; Jenkins et al., 2009).

How is one to be visible and how is one to be heard in information societies if not through the media? This question is linked to mediated youth cultures and to discussions of citizenship, especially in contemporary Western societies. For young people in the West acting on media publicity, for example in online communities, this can be a part of everyday practices as 'ubiquitous internetting', meaning the possibility to choose being online everywhere at any time (Peter and Valkenburg, 2006). However, researchers talk about 'digital divides' among the young concerning the quality of online activities. Low-speed broadband access or less up-to-date software means unequal access to opportunities for online self-expression. Other discriminatory factors among users include poor media literacy skills or even media illiteracy (Livingstone and Helsper, 2007; Jenkins et al., 2009). Jochen Peter and Patti M. Valkenburg (2006) also name an emerging approach as 'digital differentiation' focusing more on the uses and opening new gaps in relations with the media, which are based on socio-economic and cognitive resources, for example, differences in education.

Thomas Tufte and Florencia Enghel (2009) point out social realities that construct the life worlds of the young in the global context, for example, unequal living conditions and disparities, marginal and vulnerable rural livelihoods in poor areas of the globe, and illiteracy. They consider that globally, youngsters "producing citizenship 'presence" through media is a dynamic object of study; thus, social scientists should "conceptualize, understand and analyze the deeper meaning of these social and cultural practices" (Enghel and Tufte, 2011: 268-289). In general, research on children and young people in 
relations with the media is still a relatively new phenomenon and area of academic study in several countries on the globe (Carlsson, 2010).

In this paper, we broaden the gaze outside Europe to more global perspectives on youths' media participation based on the Comparative Research on Youth Media Participation (2009-2011), in which we have been studying audience activities of the young people, explored with questionnaires, interviews and media diaries among 11-18 years old in Argentina, Egypt, Finland and India. Media diaries have also been collected in Kenya. This article is based on the survey data only, because the multiple qualitative materials are in analysis. A more comprehensive report of the study will be published by Nordicom in 2014.

The media are considered to include all information technologies that offer public spaces and presentations for interacting with people as audiences, for example, radio, television, newspapers, the internet and mobile phones. The media are approached as embedded within social relationships and possibilities to participate in societies, as well as local and global communities (cf. for example, Jenkins et al., 2009).

Children and youth are seen as active actors and audiences of all media, productive individuals and members of the multiple, innovative networks through the media. Young people are considered not only as a single cultural phenomenon, or as an audience, but also as multiple groupings and actors who are shaped by sociocultural differences. For example, different age groups probably show out different kinds of participation with the media. Youngsters under 18 years are living through adolescence, and their desires and practices, including media use, are on the move (see Kotilainen and Rantala, 2009; Mannheim, $1928 / 1952)$. We cannot take it as a linear transition to adulthood, but more as shifting contextual positions, also in relations to the media: moving backwards and forwards, taking different subject positions here and now (e.g. Asthana, 2012).

This research seeks answers for complex relationships between uses, skills and participation (f.ex. Kotilainen et al., 2011; Kotilainen and Suoninen, 2013; Carpentier et al., 2013; Dahlgren, 2006; Livingstone, 2005). In this paper our aim is to add some perspectives of audiencehoods to the media-related discussions on media participation by pointing out how the practices construct youths' media participation, based on the statistical results of the research 
project. The total amount of respondents is 4,300 from all four countries. The data is weighted so that it is in balance with original sampling (but is not even intended to be nationally representative).

\section{Socio Cultural Participation through Media}

Nico Carpentier (2011) states that as a concept, participation is connected to everything and nothing, it is omnipresent and "mushroomed in the social" (e.g. 352-353). The social is re-created every day in relations with the media, when youths' participatory activities occur increasingly in the media, especially through the internet.

Three media-related participatory and political activities of the young have been named as taking place on a global scale: claiming their rights and intervening directly in national politics; strengthening the blogosphere as an alternate space for communication; and participation in movements with a global reach. Through blogs, young people' subjective, personal, emotional, every day matters shape politics when there is a possibility to publish their own problems and events. In general, Rossana Reguillo (2009: 31-34) thinks that having access to and the skills to use communicational technology strengthen young people' social participation, which weakens when "participation calls for the body".

Peter Dahlgren (2006: 273) states that civic competence cannot derive exclusively from political society, but it emerges from the overall development of the subject. Thus, "non-political contexts of civil society can have a bearing on how people engage and manage in political contexts" (Dahlgren, 2006: 273). The question of how individuals self-create themselves into citizens then get on the agenda, and additionally their skills to talk and express themselves through media, i.e. questions of social and cultural capital and identity. Then, we must consider youth participation not only as traditional political or civic engagement, but more in terms of cultural activities, even artistic ones, which can include societal and even political elements (e.g. Kotilainen and Rantala, 2009).

Since the beginning of our research in 2009 , the main working concept has been media participation (see Carpentier, 2011). Preliminarily, we defined media participation as active, at least as the subject's internal interaction with the media, for example creating one's own opinion while watching reality television programmes so that some kind of action is following: discussions with friends about the programmes or using the accessible ways of communicating with 
the programme, such as voting by means of the mobile phone. Public media participation includes positions of 'negotiator', 'visible expresser' and 'creative actor' (see Ridell, 2006). In all these positions, young people can decide to act in media publicity, for example by discussing online or creating contents in the communal radio. One specific mode of public media participation is media activism, which may include all the actions that aim to somehow change the public media or imply that the media is used in significant ways for achieving other purposes in societies, for example, as has happened during the Arab Spring 2011 (e.g. Saleh, 2013).

Nico Carpentier (2011) defines structures and elements of media participation mainly from the perspective of media production and organizations, also from this point broadening his reflection to reception and audiences. His AIP model integrates: 1) Access as presence, for example, people co-creating contents online; 2) Interaction as socio-communicative relationships; and 3) Participation as co-deciding in a communicative process. Regarding participation, he states, the "key role is attributed to power, and to equalized power relations in decision-making processes" (Carpentier, 2011: 130-131), which can vary from minimalist to maximalist power represented, for example, in alternative media.

Participation is connected to the history of democratic revolution which is characterised by a struggle to attempt to increase levels of participation in several levels and areas of societies, for example, in the arts and in the media: "Whenever s structural power imbalance occurs, attempts are organized to redress this imbalance by increasing the level of participation of the disadvantaged actors" (Carpentier, 2011: 352), like youngsters tend to be taken as minors - not as adults - in every society. A more imbalanced situation occurred, for example, in 2011, when "Egyptian youths captured the global attention, and for a short time, became the world's focus" (Saleh, 2013: 201), just at the time when we were collecting the questionnaires in rural and urban areas of the country.

Carpentier (2011) also reminds us that debates on media participation did not start with the polarization of the internet. Instead participation in and through the media has a history starting from the second half of twentieth century from the debates and practices of community and alternative media and the world communication and information order. We would also like to place its history in books, newspapers and teaching/ learning to read as part of traditional folk education and democratizing societies in the Nordic countries 
like Finland since the late 1800 century (f.ex. Kotilainen and Suoranta, 2007). Moreover, media participation has been encouraged among audiences since early projects on civic journalism (see f.ex. Ripatti-Torniainen and Hujanen, 2011).

Finally, Carpentier (2011: 356-358) presents four structuring elements of media participation from the perspective of media production, which - so we think - can be reflected also from the perspective of reception/users, in the following way:

1. The first component is identities as participatory subject positions in a communicative process, for example, positions as media producers or users. This is comparable to Ridell's roles as different agency positions as "negotiator", "visible expresser" and "creative actor" (Ridell, 2006).

2. The second element is formed by organizational structures supporting or declining the levels of participation, for example, media organization or laws and orders. From the audience perspective this can also include rules, restrictions, etc., even in a family, possibilities of learning media skills at school, even national policies on media, culture, education and youths.

3. The third element is the available technology supporting or declining the participation process, i.e. the available mode of media. Users need also access to different modes of media.

4. The fourth element is quality which the author relates to quality discourses in media production, their participatory practices, aesthetics, performances, etc. Regarding audiences and users, we can think here quality in users' activities, meaning also skills of the young user: in reception and users' production which can be evaluated based on his/her interaction.

As follows, we reflect on these elements with examples of our statistical data starting from the technology (3) as access to media. Then we turn to identities (1), focusing on the media activities connected to domestic and foreign news, to organizational structures (2), exploring how much authorities restrict the media use and to quality (4), focusing on skills of the user.

Before that, we shortly contextualize the South and the North in this research. 


\section{Perspectives from the South and the North}

The transnational comparative approach has practically become a norm of the research on media products and their uses (Hanitzsh and Esser, 2012). The nature of this comparative study is explorative and descriptive with limited number of cases as different cultures, nations and media environments (Vliegenthart, 2012: 487). The aim is to make visible young people with their multiple voices as audiences participating in societies in these cultures through the media (Livingstone, 2012).

Comparative Research on Youth Media Participation is focused mainly on the South, since the only participating northern country is Finland, a small country with 5,4 million inhabitants, situated in Northern Europe (alongside other Nordic countries such as Sweden, Norway and Denmark). Finland cannot, therefore, form the total picture of 'the North'. Argentina, Egypt and India, which represent the South, form a mixture of different cultures; furthermore, each has millions more inhabitants than Finland. Focus on the South is valid because of the ever-increasing amount of Western research on young people and the media, so there is a need for more child and media research in that area (see e.g. Carlsson, 2010). Increasing the perspectives from the South has also been the main criterion for the selection of countries for the study. In India the project was carried out in one state only, namely Gujarat in northern India. As India is a huge country both in the size of its geography and population, we will refer only to Gujarat when presenting the empirical results of the project.

The four participating countries differ considerably from each other when looking at any international background statistics. We will describe the countries briefly by using three different statistical indexes which are each a combination of a number of statistical instruments. Human Development Index (HDI) is a combination of indicators of life expectancy, educational attainment and income. In the data gathering year 2010, Finland was ranked $16^{\text {th }}$ (among 169 UN member countries) with very high human development, Argentina $46^{\text {th }}$ with high human development while Egypt was ranked $101^{\text {st }}$ and India $119^{\text {th }}$ with moderate human development (Human Development Report, 2010). The Gender Inequality Index (GII) reflects women's disadvantage in three dimensions - reproductive health, empowerment and the labor market. The index shows the loss in human development due to inequality between female and male achievements in these areas. According to the Human De- 
velopment Report 2013, Finland ranked $6^{\text {th }}$ on this index, Argentina was $71^{\text {st }}$, Egypt $126^{\text {th }}$ and India $132^{\text {nd }}$. The Press Freedom Index compiled by Reporters Without Borders (reflects the degree of freedom that journalists, news organizations, and citizens enjoy in each country, and the efforts made by the authorities to respect and ensure respect for this freedom. According to this index, in 2010 Finland is well situated for press freedom (ranking $1^{\text {st }}$ among 178 countries),

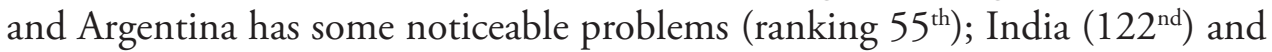
Egypt $\left(127^{\text {th }}\right)$ both have a difficult situation in press freedom (but none has been classified as having a very difficult situation).

With a combination of these three indexes together with the Gini Index, which reflects the economic inequality within a country (Human Development Report, 2010) it is possible to obtain a brief insight into these four countries. Finland is a north European, mainly Protestant, Christian country, with very high human development, good gender equality, quite good economic equality and good press freedom. Argentina is a southern American mainly Catholic, Christian country, with high human development, some problems with press freedom, moderate gender equality but quite high economic inequality within the country. Egypt is a northern African, mainly Muslim country and India a South Asian, mainly Hindu country, but their statistical profiles are quite similar: moderate human development, low gender equality, moderate economic equality and with a somewhat difficult situation in press freedom.

Although Finland is the smallest participant, the practicalities of the study have been mainly Northern and Western. The process has been led from Finland (including statistical analyses and three post doctoral researchers in the project), with the other countries contributing with one or two researchers. However, northerners cannot comment on media and information literacies in these southern countries without local expert researchers; not even through statistics. This is why, in the planning of the study's implementation, questionnaires and interpretations of the analysis have been a collaborative process with native researchers from participating countries. There has been a responsible researcher in every country for the collection of the data and for the whole study locally.

The primary focus has not been on looking for differences between countries, as these would be quite obvious in the case of such different countries; rather, it has been on looking for similarities in youth media participation 
and in practices of media and information literacies. However, on the basic statistical level presented in this article, the four countries appear to differ from each other significantly. Statistically, the study concentrates on comparisons between, for example, different age groups, gender and rural vs. urban areas, within countries and between countries. The survey sampling is based on four criteria: age, gender, geographical location, and the socio-economic background of the young people.

The first major decision to be made before sampling was the age of the informants. We wanted to include several age groups in order to recognize the age trends among young people. 11-12 year-olds were selected as the youngest age group, because at this age pupils are able to fill in written questionnaires without major difficulties. 17-18 year-olds were selected as the oldest age group, as they could be reached through schools in all participating countries. We do, however, understand that when collecting the data through schools we could reach only a part of the older teenagers especially in Egypt and Gujarat; according to UNESCO statistics about half of the adolescents in India and two thirds of the adolescents in Egypt attend secondary schooling (UNICEF, 2011). In this article we concentrate on the two older age groups as parts of the data used was not available from the youngest.

We decided to concentrate the data collection in each country on two geographical areas: one urban and one rural. All the data, including interviews, media diaries and questionnaire data were to be collected from these two geographical areas if possible, practically in the capital of the country/state and one rural area far from the capital. In all participating countries/states half of the data were gathered in the selected urban area and half in the selected rural one, independently of the distribution of population between the two areas. According to UN statistics, in 2010 the proportion of urban population varied from 30\% in India and 43\% in Egypt to 64\% in Finland and 92\% in Argentina (World Development Indicators, 2012).

Furthermore, the definition of 'urban' varies from country to country. In Finland, the urban data were collected in the Helsinki metropolitan area with its approximately one million inhabitants (the city of Helsinki alone has about 500,000). In Argentina, urban meant Buenos Aires with almost three million inhabitants and in Cairo with almost seven million inhabitants. In Gujarat 
the urban data were gathered in two separate urban areas: Ahmedabad, with some six million inhabitants, and Vadodara with around two million.

While doing research in four different cultures on four different continents we encountered various obstacles, starting with practical problems, as the countries are situated in different hemispheres and the organization of the school year varies greatly from country to country. Some basic cultural differences had to be taken into account when preparing the questionnaire; for example, a question about "searching for information about sexuality" could not be included in the questionnaire in Argentina and Egypt for religious reasons. Neither could we include questions that would have suggested any criticism of media censorship in Egypt as it is a governmental practice there.

There were some obstacles we could not have been prepared for. We lost track of some Indian and Egyptian questionnaires for some weeks, as they were held up at airports because of the heavy blizzards in Europe. The data collection in Egypt was also interrupted for a couple of months because of the events of the Arab Spring. In fact, questionnaires from rural Egypt were collected only after the revolution.

In hindsight, although we tried to be open to different cultures, it is obvious that some amount of 'Western cultural imperialism' was inevitable; this has a great deal to do with the fact that the theories and former research originate mainly in the West. Due to limited budget and tight timetable for data collection we did not conduct a pilot study, yet it became evident that piloting the questionnaire in all participating countries would have been an important part of the research process. When analysing the collected survey data it became obvious that large parts of the questionnaire were misunderstood by the Gujarati respondents and we were forced to leave Gujarat out of a considerable part of the statistical analysis; the options selected in some questions were totally illogi$\mathrm{cal}$ and so large percentages of respondents reported to have been involved, for example, in producing television programs that these answers were just impossible to explain other than by misunderstandings of the questions. 


\section{Comparative Results on Youth Media Participation}

\section{Technologies as Levels of Access}

In the questionnaire, the young respondents were asked about their access to ten different media technologies (newspapers, magazines, radio, television, video or DVD players, music players, game consoles, computers, Internet connections and mobile phones), regarding whether these were in their personal possession, available at home, available somewhere else, or not available at all. On average, the Finnish 14-18 year-olds respondents had access to 9.3 of these devices at home, while in Argentina this figure was 8.2, in Egypt 6.5, and in Gujarat 5.9. In all the countries, home access to several media devices was more common in urban than in rural areas, but the differences in media access between rural and urban areas were the greatest in Egypt and Gujarat. The differences between countries remain when we look at the number of media devices that are not available (either at home or anywhere else): in Gujarat the average number of totally non-available media devices is 2.6, in Egypt 1.5, in Argentina 0.8, and in Finland 0.2.

Based on the results, different developmental phases of user cultures can be termed as 'non-access at home', 'access at home' and 'personal access at home'. In rural areas in the South, especially Gujarat, young people had no media access at home. The next phase, 'access at home' was visible particularly in Egypt, where access was found in several homes, mainly in urban but also rural areas. In Finland (North), the young generation is living in a highly mediated culture where the young respondents often have personal access to a large number of different media at home, and there is no difference between urban or rural areas. Argentina (South) appears to be an in-between country, having all these phases in process (Kotilainen \& Suoninen, 2013).

In each country over $95 \%$ of respondents had access to television and mobile phones, either at home or somewhere else. The inequalities in access between urban and rural areas are clear when we look in more detail at the access to one particular medium, the Internet. In Gujarat, two-thirds of urban respondents have online access at least somewhere, while two-thirds of rural respondents have no access at all. In Egypt over $80 \%$ of both urban and rural youngsters have Internet access, while two-thirds of urban respondents, but only half of rural ones, had Internet available at home. In Argentina, there was a smaller 
difference in access both inside and outside the home. In Finland practically everyone had Internet access at home, and in urban areas young people could more often access the Internet in their own rooms or through a personal device.

Figure 1: Access to Internet in urban and rural areas, percentage of 14-18 year-old respondents by country/state

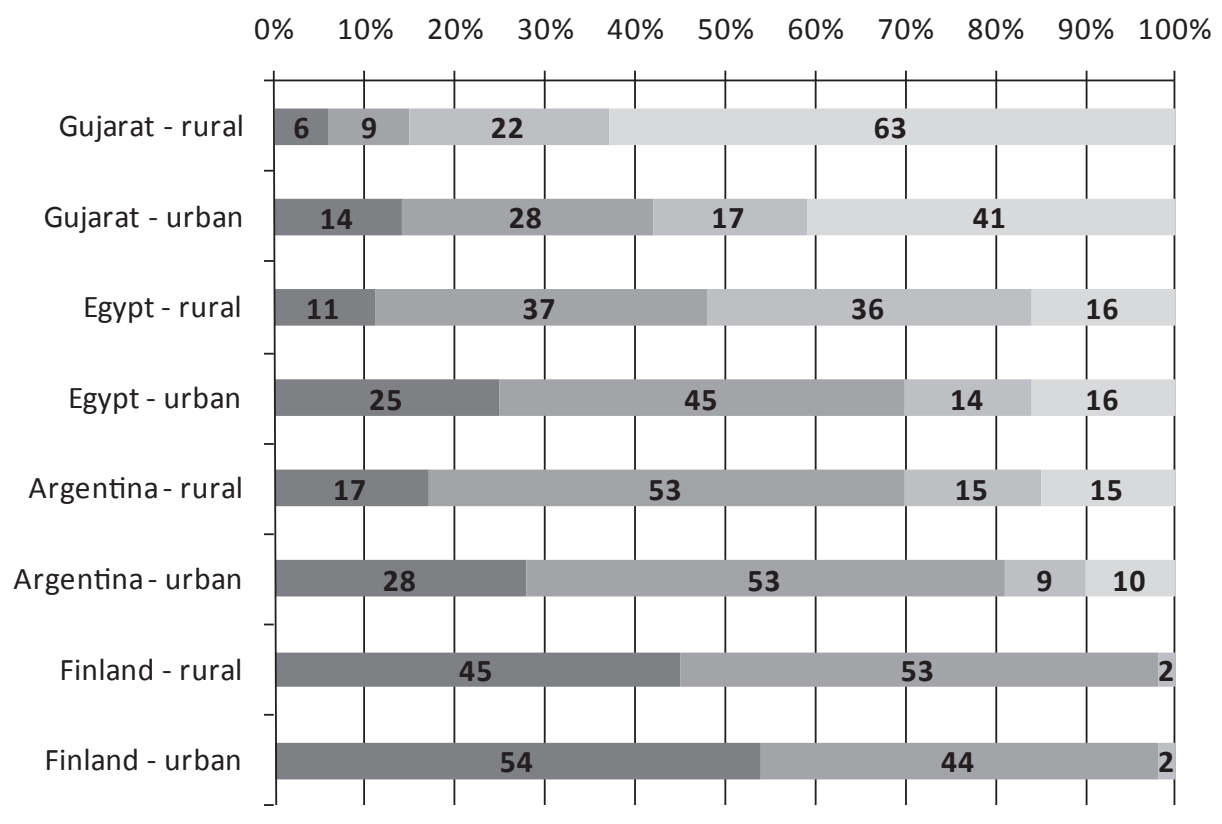

Personal Athome Somewhere else Not available

The use of a given medium is quite obviously connected to the access to it. Therefore, the number of different media used weekly varied greatly depending on the number of different media devices available. The respondents were asked about the use of twelve different types of media (newspapers, magazines, online papers, books, television programmes, videos or DVDs, radio, music recordings, digital games, Internet, computer for other purposes than gaming or using the Internet, and mobile phone). The Finnish 14-18 year-old respondents used an average of 8.0 of these weekly; in Argentina the corresponding figure was 7.2, in Egypt 5.6 and in Gujarat 4.8. In Egypt and Gujarat, boys and urban residents used a significantly wider selection of media weekly than did girls or 
the rural young people; in Finland and Argentina, these differences were small or nonexistent.

\section{Identity as media activities (connected to domestic and foreign news)}

The questionnaire contained questions about media activities connected to several media contents, but in this article we will look only those connected to domestic or foreign news. Two-thirds of all the respondents in the two older age groups (14-18 year-olds) followed domestic or foreign news through the media; this percentage was $91 \%$ in Finland, $78 \%$ in Gujarat, $77 \%$ in Argentina but only $46 \%$ in Egypt. About half of all respondents in these age groups also discussed news with friends or family: this percentage was highest in Finland and lowest in Gujarat. Fifteen per cent of teenagers also said they participated in public media discussions on this subject, $12 \%$ submitted material produced by others to their friends through the media, and 7\% said they created and published material on this subject.

Figure 2: Media activities connected to domestic or foreign news, percentage of 14-18-yearold respondents by country/state.

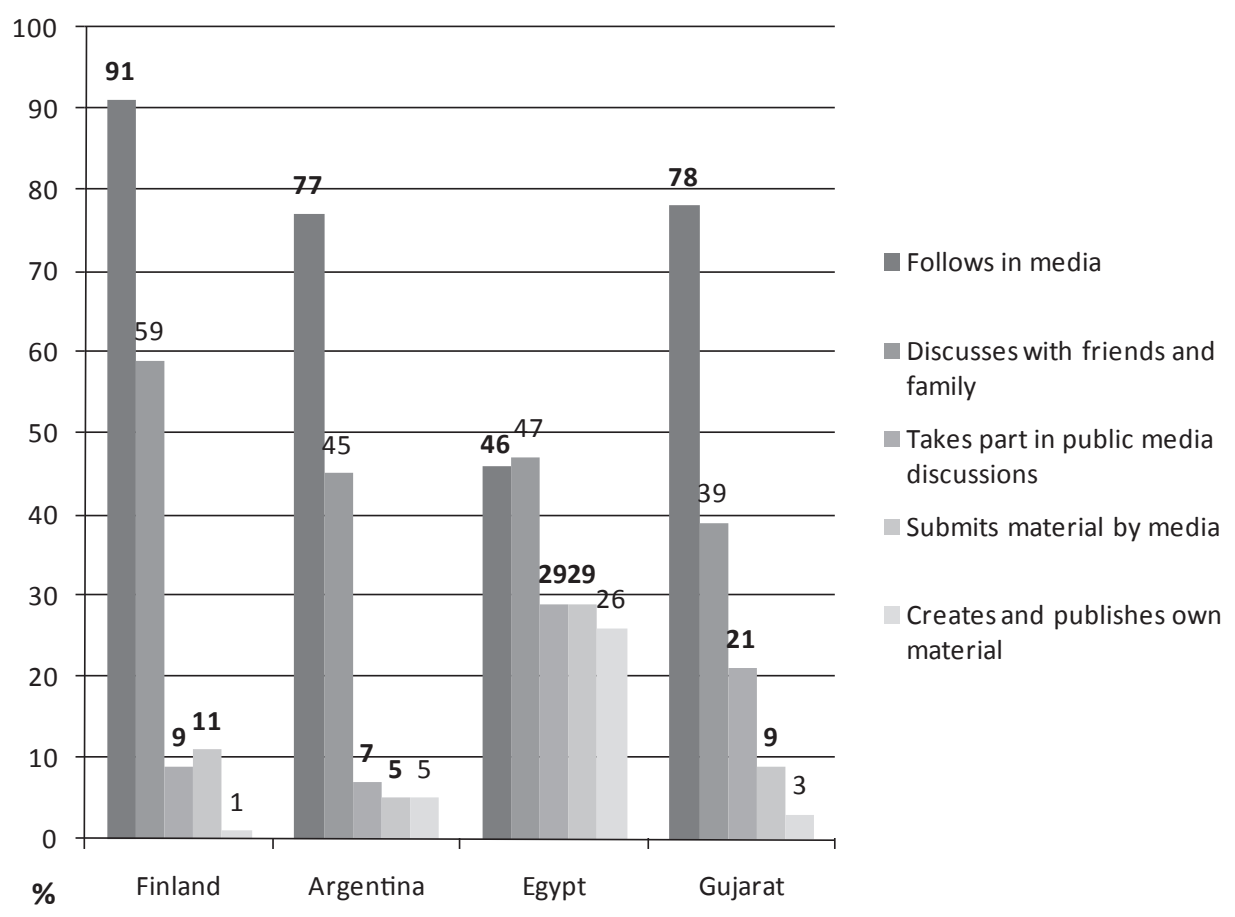


The Egyptian respondents reported a much more active role in submitting and creating news material through media than did the young people in the other countries. This is quite understandable, considering that the data were gathered in Egypt mostly during December 2010 and January 2011, just before and during the Arab Spring. 29\% of the Egyptians participated in public media discussions and $42 \%$ of them either submitted or created news material. A fourth of Egyptian 14-18 year-olds reported having published self-made media material on the domestic news, while only $2 \%$ had done this in other countries.

The analysis of research data is still in process but even the preliminary analysis shows clearly that both access and interest play an important role in media participation. With easy access even a moderate amount of interest can lead to a considerable high rate of use of media content, and with high enough interest while submitting or creating media contents requires both access and higher level of interest. And this comes out clearly from the Egyptian data where the easy access to new media technology was higher in urban than rural areas while the rural data was collected nearer in time to the Egyptian revolution. A higher proportion of the rural respondents followed the news content in the media and discussed it with their family and friends (over three fourths of the respondents in rural areas in comparison with about one third in urban areas) while submitting or creating media material was more common in urban areas (almost half of the respondents in urban areas compared to less than one third in rural areas).

Almost two thirds of the 14-18 year old respondents had used media for publishing their own opinions about civic or cultural issues. $65 \%$ of the Finnish, $60 \%$ of the Argentinean and $54 \%$ of the Egyptian respondents said that they had used some media "if you want to make your opinions heard" (phrasing of the question). (For reasons previously explained in this article Gujarat data was excluded from this analysis.) There was a big difference between countries in what types of media young people used for publishing their own opinions. In Finland only $11 \%$ of the respondents used traditional media (printed newspapers or magazines, radio or television) for this purpose as $64 \%$ used Internet media (online papers, discussion groups, social networking sites or other Internet sites). Also in Argentina and Egypt Internet based media was used by more respondents than traditional media, but the difference between these two types was much smaller than Finland. Traditional media was used by $53 \%$ in Argentina and $41 \%$ in Egypt while Internet based media was used by $53 \%$ in Argen- 
tina and 52\% in Egypt. Worth noticing is also that 61\% of Finnish respondents had published opinions about cultural issues (e.g. music and films) while only $41 \%$ had published opinions about civic issues (social issues, politics, environmental issues or human rights). In Argentina 52\% had published on cultural issues and $49 \%$ on civic issues. $47 \%$ of the Egyptian respondents had published opinions about culture and 52\% opinions about civic issues.

Figure 3: Using media for making opinions about cultural and civic issues heard, percentage of 14-18-year-old respondents by country

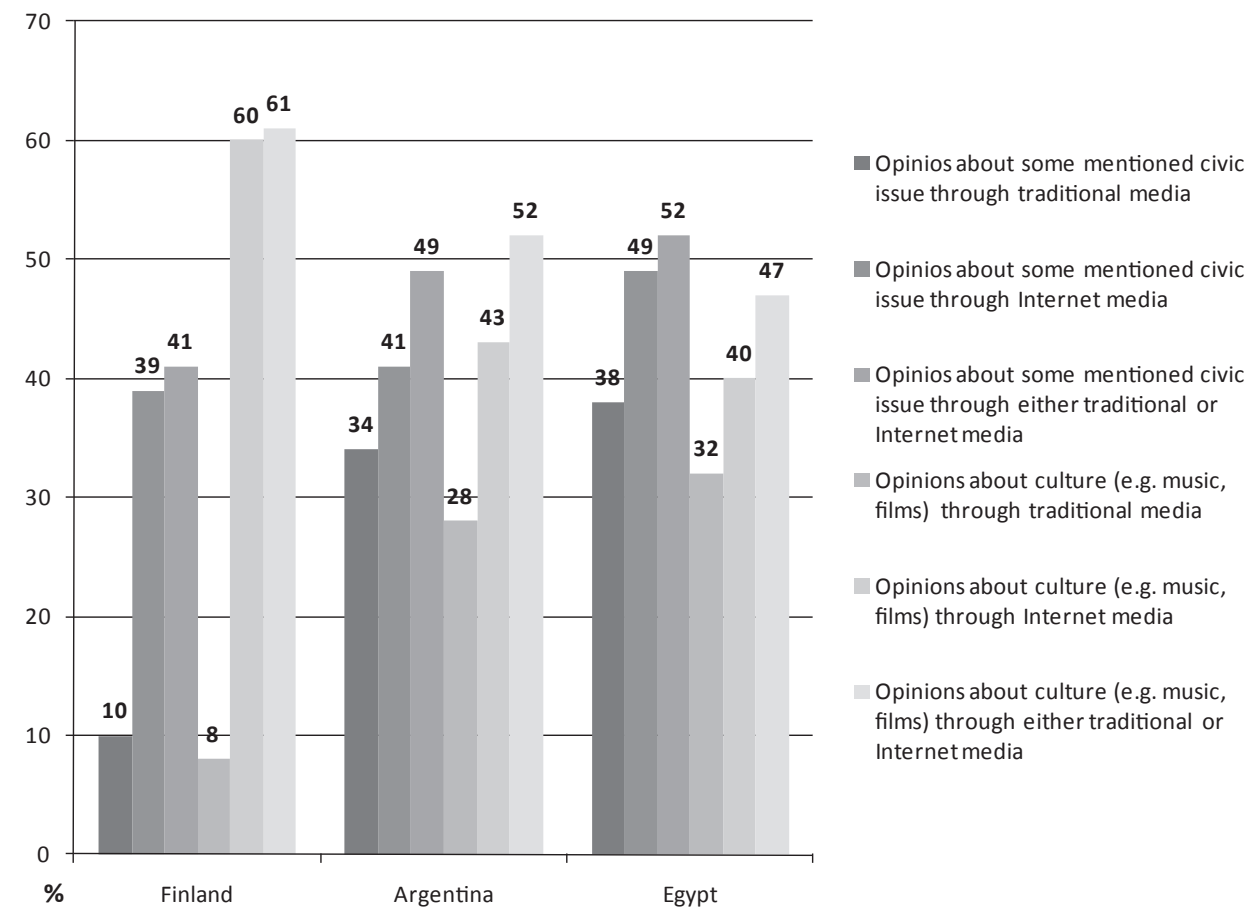

In Finland and Argentina there were no big differences between urban and rural respondents on whether they had published their opinions in media. In Egypt this difference was, however, huge: over three fourths of urban respondents said that they had used media this way while this was the case for only a quarter of the rural respondents. This difference between urban and rural Egyptian youngsters could be explained with two different reasons. Firstly, the home access to different media - especially Internet - was much higher in urban and rural areas and therefore respondents living in rural areas might not have oppor- 
tunities and/or knowledge to use media for publishing their own opinions. Secondly, the data gathering in Egypt took place just before (or after) the Egyptian revolution in January 2011 and the revolutionary activities took mainly place in Cairo where the urban data were gathered; the exceptional circumstances most certainly had increased willingness to publish opinions about civic issues among youngsters living in Cairo, in the middle of the civic protests.

\section{Organizational structures as restrictions for media use}

The questionnaire included questions about whether the respondents felt that certain authorities restricted the media material that they could use. Three fourths of the Argentine, little less than two thirds of the Egyptian and one third of the Finnish respondents said that either public authorities (governmental, religious or educational authorities) or parents and family restricted their media uses. In Argentina more youngsters felt that their media uses were restricted by public authorities while in Finland and Egypt more restrictions came from the family. (Again, for the reasons explained previously in this article, Gujarat data were excluded from this analysis.)

Figure 4: Authorities restricting the media content used, percentage of 14-18 year-old respondents by country

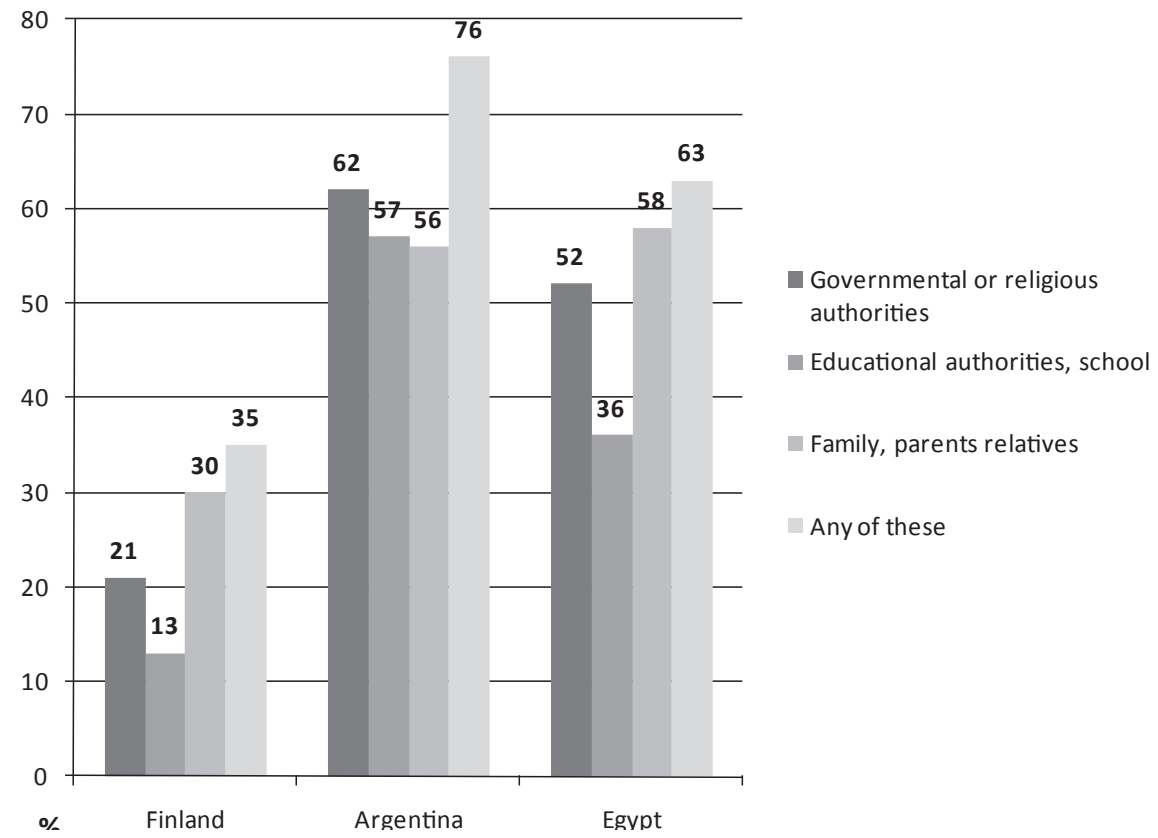


The Finnish respondents felt that family restricted their media uses more than public authorities or school, while Argentine respondents felt a lot of restrictions from both. In Egypt over half of the respondents said that either governmental or religious authorities restricted their media uses while only one third felt restrictions from school. In Egypt and Argentina 14-18 year olds felt that governmental authorities were restricting especially material presented in newspapers and television while in Finland the Internet was felt to be restricted by governmental authorities and laws. In this aspect the Finnish data could seem a bit illogical, but during the last few years there have been several cases of people (including some politicians) accused in court for publishing racist writings on the Internet.

\section{Quality: skills as media critics}

The research shows the relation between one's critical attitude towards the media and the political situation. A critical attitude towards the media seems to develop with age; for example, older respondents trusted advertisements and newspaper news less often than younger respondents did. Egypt was an exception to this rule, however, as the older respondents seemed to be less critical than the younger ones. It is, however, impossible to say whether Egyptian respondents were totally honest with their answers: the older respondents might have been just more aware that the media censorship was governmental policy and therefore mistrust towards newspapers could be interpreted as mistrust towards the (authoritarian) government, and as the questionnaires were filled in at school the older respondents might have been cautious about revealing their true opinions (Kotilainen and Suoninen 2013).

In all, the Egyptian young people seemed to be far less critical of media than were their counterparts in the three other countries. For example, in Egypt $80 \%$ of the $14-18$ year-old respondents totally agreed and $95 \%$ either agreed or totally agreed with the statement "If news is printed in a newspaper, it must be true", while in the other countries only less than a fifth totally agreed and about half agreed or totally agreed.

It was also more common among Egyptian respondents to agree with the statement "Commercials and advertisements give correct information about products". In Egypt 31\%, in Gujarat 14\%, in Argentina 9\% and in Finland $3 \%$ of the $14-18$ year old respondents totally agreed with this statement. The 
percentages of those who either agreed or totally agreed with the statement were 47\% in Egypt, 52\% in Gujarat, 31\% in Argentina and 21\% in Finland.

On the other hand, Egyptian respondents did hope for more press freedom as $57 \%$ of them totally agreed with the statement "We need mass media to have more freedom and independence". In other countries this statement was phrased "We need more independent media in order to get publicity to a wider range of social and political views" and 34\% of the Argentine, $26 \%$ of Gujarati and $7 \%$ of Finnish respondents totally agreed with this statement.

One important media skill is the ability to differentiate between factual and fictional media content. Most respondents appeared confident in their ability to make this distinction, as the majority of all young people either totally agreed or agreed with the statement "It is easy to distinguish between informative programming and entertainment in television and radio programming". In Finland $92 \%$, in Argentina 89\%, in Egypt 79\% and in Gujarat 82\% agreed with this statement. Confidence in one's own abilities might not, however, mean that the person is actually able to make a distinction between factual and fictional content, as younger respondents were somewhat more confident of their own abilities than older ones were; this was especially the case in Finland and Argentina, while in Egypt there was no major difference between age groups and in Gujarat the confidence in one's ability to make this distinction increased with age. However, in all countries it was more common among younger than older respondents to agree with the statement "There are no manuscripts in realitytelevision programs but they show things the way they really happen". Maybe the older respondents (especially in Finland and Argentina) were less confident about their own ability to distinguish between reality and fiction in the media as they were more aware of the different genres that intentionally blur the difference between fact and fiction, reality and fantasy.

\section{Conclusion: Aspects of Media Participation among Young People}

Following Carpentier (2011), the research confirms that media participation needs technological and organizational structures as basic possibilities for participatory activities through the media, as access and possibilities to use the media for public participatory purposes. Regarding youngsters, total freedom in a family may not become true even in a full democracy. Carpentier's "iden- 
tity" in relations with media participation meaning cultural roles and choices of media activities seem to be dependent on the youngsters' need to retrieve and communicate information (cf. Kotilainen and Suoninen, 2013).

Human based needs and motivation to communicate show out an important basis for participatory actions through the media, i.e. sociocultural modes of expression together with the access. We conclude with these as preconditions of media participation together with a suggestion for a differentiation of aspects of youth media participation as a four square, based on a) levels of access and b) levels of interest and motivation following Carpentier's (2011) "minimalist vs. maximalist" participation, added with "mixed" meaning the situation in the middle and/ or including both minimalist and maximalist (see Figure 5).

Figure 5: Aspects of youth media participation

\begin{tabular}{|l|l|l|l|}
\hline & \multicolumn{3}{|l|}{ Level of access to different media } \\
\hline $\begin{array}{l}\text { Level of interest } \\
\text { and motivation }\end{array}$ & $\begin{array}{l}\text { Low } \\
\text { (non-access at home) }\end{array}$ & $\begin{array}{l}\text { High } \\
\text { (access at home / personal } \\
\text { access) }\end{array}$ \\
\cline { 2 - 4 } & Low & $\begin{array}{l}\text { low/non-versatile media } \\
\text { use } \\
\text { minimalist participation } \\
\text { [rural Argentina] }\end{array}$ & $\begin{array}{l}\text { high/versatile media use } \\
\text { mixed participation (high } \\
\text { density, low intensity) } \\
\text { [Finland, urban Argentina] }\end{array}$ \\
\cline { 2 - 4 } High & $\begin{array}{l}\text { constrained media use } \\
\text { mixed media participa- } \\
\text { tion (low density but high } \\
\text { intensity) } \\
\text { [rural Egypt, Gujarat] }\end{array}$ & $\begin{array}{l}\text { high/versatile media use } \\
\text { maximalist participation } \\
\text { [urban Egypt] }\end{array}$ \\
\hline
\end{tabular}

The results show more differences than similarities, also inside countries. This is natural because of the socio-economic and societal differences including societal contexts in the participating countries. Based on the results, different developmental phases of user cultures can be termed as 'non-access at home', 'access at home' and 'personal access at home'. In rural areas in the South, especially Gujarat, young people had no media access at home, and in the case of the Internet they had no access to this medium anywhere. The next phase, 'access at home', was visible particularly in Egypt, where access was found in several homes, mainly in urban but also rural areas. In Finland (North), one 
can say that the young generation has been born into a highly mediated culture. These young respondents have mostly personal access to media at home, particularly to the Internet, and there is no difference between urban or rural areas. Argentina (South) appears to be an in-between country, having all these phases in process (e.g. Kotilainen and Suoninen, 2013).

Based on the results, we can say that the more young people with access to multiple media, the more multiple their uses of media appear to be. Moreover, the political situation as an imbalance of structural power in everyday life frames the level and modes of media participation (Carpentier 2011: 352). According to the results, Egyptian respondents reported a much more active role in submitting and creating news material through the media than did their counterparts in the other three countries. This is quite understandable, as the data were gathered in Egypt just before and during the Arab Spring.

The research shows that participation through the media and an interest in societal issues via the media, do not seem to be dependent on the technical device - but more on the need and motivation. Where Internet connections are not available, radio, television, newspapers and magazines inform youngsters and promote discussions among them. As Ibrahim Saleh (2013) notes, the limited access to online media has been added with oral communication as "through word of mouth" in the Egyptian revolution among young activists and the rest of the population. Moreover, Kotilainen et al. (2011) notice, the difference seems to be the mode of media participation: when a 14 year-old in Finland is able to enter an international political movement online, youngsters of the same age in rural areas of India and Egypt reflect on national political themes via (traditional) mass media with their friends, family or by themselves.

In all the above mentioned media activities young people take different kinds of positions as users, i.e. identities of media participation (Carpentier, 2011). Public media participation includes positions of 'negotiator', 'visible expresser' and 'creative actor' (e.g. Ridell, 2006), which seem to take place when the access is easy and personal motivation high, as has been the case among youngsters in Cairo in this study (see Saleh, 2013).

Regarding the modes of youth media participation, the research confirms that we must consider youth participation not only as traditional political or civic engagement, but more in terms of cultural activities, which may include societal and even political elements. Most youngsters in peaceful democra- 
cies such as Finland are more motivated in cultural issues and participatory activities close to their living environment and thus participate, for example, in voting online for better food in their school (e.g. Kotilainen and Rantala, 2009; Dahlgren, 2006). Also in this case, motivation plays an important role in participation, also through the media.

We conclude with the notice of Carpentier's (2011) fourth constructive element of media participation as quality. The author relates quality to the evaluative discourses in media production, their participatory practices, aesthetics and performances, which are all practices that need skills in media use. In this paper, we have looked at only skills in media critics which seem not to relate to the stage of participation. A critical attitude towards media seems to develop with age; on the one hand, only Egypt (with its exceptional political situation) was an exception to this rule, as the older respondents were less critical than the younger, but on the other hand, Egyptian respondents longed for more freedom and independence for the media. Following Kotilainen and Suoninen (2013), this study suggests that it is important to emphasize media criticism, ethical reflections and skills for creative public expression as media and information literacies together with participatory activities in relation to the media. This is important in enhancing dialogue, especially in imbalanced power structures which call for public media participation among the young. Moreover, the study encourages more research on media participation from the perspectives of skills and learning participatory practices, especially among children and young. 


\section{References}

Asthana, S. (2012). Youth Media Imaginaries from around the World. New York: Peter Lang.

Carlsson, U. (ed.) (2010). Children and Youth in the Digital Media Culture. Gothenburg: The International Clearinghouse on Children, Youth and Media \& NORDICOM.

Carpentier, N., Schroder, K.C., Hallet, L. (eds.) (2013). Audience Transformations. Shifting Audience Positions in Late Modernity. London: Routledge.

Carpentier, N. (2011). Media Participation. A site of ideological-democratic struggle. Bristol \& Chicago: Intellect.

Dahlgren, P. (2006) Doing Citizenship. The Cultural Origins of Civic Agency in the Public Sphere. European Journal of Cultural Studies, 3(9), 267-286.

Enghel, F. \& Tufte, T. (2011). Citizenship Practices among Youth. Exploring the Role of Communication and Media. In Feilitzen, C., Carlsson, U. \& Bucht, C. (eds.), New Questions, New Insights, New Approaches. Contributions to the Research Forum at the Worlds Summit on Media for Children and Youth 2010. Gothenburg: The International Clearinghouse on Children, Youth and Media \& NORDICOM, pp. 261-270.

Hanitzsh, T. \& Esser, F. (2012). Challenges and Perspectives of Comparative Communication Inquiry. In Esser, F. \& Hanitzsh, T. (eds.), The Handbook of Comparative Communication Research. London: Routledge, pp. 501-516.

Hodkinson, P. \& Deicke, W. (eds.) (2007). Youth Culture. Scenes, Subcultures and Tribes. London: Routledge.

Human Development Report 2010. (2010). New York: United Nations Development Programme. Accessed 20.9.2013. URL: http://hdr.undp.org/en/ reports/global/hdr2010/.

Human Development Report 2013. (2013). New York: United Nations Development Programme. Accessed 20.9.2013. URL: http://hdr.undp.org/en/ reports/global/hdr2013/. 
Jenkins, H. et al. (2009). Confronting the Challenges of Participatory Culture: Media Education for the $21^{\text {st }}$ Century. Cambridge \& London: The MIT Press \& MacArthur Foundation. Accessed 20.9.2013. URL: https://mitpress.mit. edu/books/confronting-challenges-participatory-culture.

Kotilainen, S. \& Suoninen, A. (2013). Cultures of Media and Information Literacies among the Young. South-North Viewpoints. In Carlsson, U. \& Culver. S-H. (eds.), Media and Information Literacy and Intercultural Dialogue. MILID Yearbook 2013. Gothenburg: The International Clearinghouse on Children, Youth and Media \& NORDICOM, pp. 141-162.

Kotilainen, S., Suoninen, A., Hirsjärvi, I. \& Kolomainen, S. (2011). Youngsters' Expressions of Responsible Citizenship through Media Diaries. In Feilitzen, C., Carlsson, U. \& Bucht, C. (eds.), New Questions, New Insights, New Approaches. Contributions to the Research Forum at the Worlds Summit on Media for Children and Youth 2010. Yearbook 2011. Gothenburg: The International Clearinghouse on Children, Youth and Media \& NORDICOM, pp. 213-225.

Kotilainen, S. \& Rantala, L. (2009). From Seekers to Activists: Characteristics of Youth Civic Identities in Relation to Media. Information, Communication \& Society, 12(5), 658-677.

Kotilainen, S. \& Suoranta, J. (2007). Mot en dialogisk mediepedagogikk i Finland. In Vettenranta, S. (ed.), Mediedanning og mediepedagogikk: Fra digital begeistring til kritisk dommakraft. Oslo: Gyldendahl Akademisk, pp. $104-123$.

Livingstone, S. (ed.) (2005). Audiences and Publics: When Cultural Engagement Matters for the Public Sphere. Bristol: Intellect.

Livingstone, S. (2012). Challenges to Comparative Research in a Globalizing Media Landscape. In Esser, F. \& Hanitzsh, T. (eds.), The Handbook of Comparative Communication Research. London: Routledge, pp. 415-429.

Livingstone, S. \& Helsper, E. (2007). Gradations in Digital Inclusion: Children, Young People and the Digital Divide. New Media \& Society, 9(4), 671-696.

Mannheim, K. (1928/1952). The Problem of Generations. In Essays on the Sociology of the Knowledge. London: Routledge \& Kegan Paul, pp. 276-322. 
Peter, J. \& Valkenburg, P. M. (2006). Adolescents' internet use: Testing the "disappearing digital divide" versus the "emerging digital differentiation" approach”. Poetics, 34, 293-305.

Press Freedom Index. Reporters Without Borders. Accessed 20.9.2013. URL: http://en.rsf.org/press-freedom-index-2010,1034.html.

Reguillo, R. (2009). The Warrior's Code? Youth, Communication and Social Change. In Tufte, T. \& Enghel, F. (eds.), Youth Engaging with the World. Media, Communication and Social Change. Gothenburg: The International Clearinghouse on Children, Youth and Media \& NORDICOM, pp. 21-42. Ridell, S. (2006). Yleisö. Elämää mediayhteiskunnan normaalina jäsenenä. In Ridell, S., Väliaho, P. \& Sihvonen, T. (eds.), Mediaa käsittämässä. Tampere: Vastapaino, pp. 233-257.

Ripatti-Torniainen, L. \& Hujanen, J. (2011). Cultivating the Democratic Mind: The Understated Adult Educational Characteristic of Public Journalism. Javnost - The Public, 18(2), 37-52.

Saleh, I. (2013). Convergence Culture and Youth Activism in Egypt. New Social Movements on the Block. In Carlsson, U. \& Culver. S-H. (eds.), Media and Information Literacy and Intercultural Dialogue. MILID Yearbook 2013. Gothenburg: The International Clearinghouse on Children, Youth and Media \& NORDICOM, pp. 201-214.

Tufte, T. \& Enghel, F. (eds.) (2009). Youth Engaging with the World. Media, Communication and Social Change. Gothenburg: The International Clearinghouse on Children, Youth and Media \& NORDICOM.

UNICEF (2011). Adolescence. An Age of Opportunity. The State of the World's Children 2011. New York: UNICEF. Accessed 20.9.2013. URL:

http://www.uis.unesco.org/Library/Documents/state-world-children-adolescence-age-opportunity-education-2011-en.pdf.

Vliegenthart, R. (2012). Analyzing Comparative Data: Opportunities and Challenges. In Esser, F. \& Hanitzsh, T. (eds.), The Handbook of Comparative Communication Research. London: Routledge, pp. 486-497.

World Development Indicators 2012 (2012) Washington D.C.: The World Bank. Accessed 20.9.2013. URL: http://www.uis.unesco.org/Library/Documents/world-development-indicators-education-2012-en.pdf. 